\title{
The cytotoxicity of cyclophosphamide is enhanced in combination with monascus pigment
}

\author{
Hiromi Kurokawa, ${ }^{1, *}$ Atsushi Taninaka, ${ }^{2}$ Hidemi Shigekawa, ${ }^{2}$ and Hirofumi Matsui ${ }^{1,3}$ \\ ${ }^{1}$ Algae Biomass Research and Development, ${ }^{2}$ Graduate School of Comprehensive Human Sciences, and ${ }^{3}$ Faculty of Medicine, University of Tsukuba, \\ 1-1-1 Tennodai, Tsukuba 305-8575, Japan
}

(Received 7 December, 2020; Accepted 24 January, 2021)

\begin{abstract}
Monascus pigment is derived from red-mold rice fermented by monascus purpureus and utilized as a natural coloring agent and natural food additive in East Asia. Monascus pigment works as a radical scavenger. Some antioxidant combine cancer chemotherapy to protect normal tissue because chemotherapy induce side effect for normal tissue. This combination therapy can attenuate the cytotoxicity of anticancer drugs by antioxidants effects. However, the effect of this combination therapy for cancer cells dose not investigate enough. In this study, we investigated the combination effect of antioxidants and anticancer drugs. We selected an antioxidant as monascus pigment and following four anticancer drugs: doxorubicin, tamoxifen, paclitaxicel, and cyclophosphamide. Combination treatment with monascus pigment and cyclophosphamide enhanced the cytotoxicity of cyclophosphamide. Moreover, this combination treatment accelerated apoptosis. The spot on TLC assay board of the monascus pigment and cyclophosphamide mixture is different from the spot of monascus pigment alone and cyclophosphamide alone. The interaction between monascus pigment and cyclophosphamide can produce some cytotoxicity compounds or accelerate intracellular cyclophosphamide accumulation. Hence, we concluded that the interaction of both cyclophosphamide and monascus pigment involved enhancement of cyclophosphamide cytotoxicity.
\end{abstract}

Key Words: Monascus purpureus, cyclophosphamide, apoptosis, BCL-2, Bax

M onascus pigment (MP) is derived from red-mold rice fermented by Monascus purpureus and utilized as a natural coloring agent and natural food additive in East Asia. ${ }^{(1,2)}$ The components of MP have been identified. Monacolin $\mathrm{K}$ inhibit the enzyme 3-hydroxy-3-methyl glutaryl coenzyme A (HMG-CoA) reductase, which catalyzes the reduction of HMG-CoA to mevalonate. $^{(3)}$ The same substance approved by the US Food and Drug Administration in 1987 as lovastatin. ${ }^{(4)} \gamma$-Aminobutyric acid and dimerumic acid possessd antihypertensive effects and antioxidant activities. ${ }^{(5-7)}$ Ankaflavin and monaphilone $\mathrm{A}$ inhibited tumor growth by induce of apoptosis or anti-inflammatory effect. ${ }^{(8)}$

Cancer patients were estimated at 18.1 million new cases and 9.6 million deaths by the World Health Organization in $2018 .{ }^{(9)}$ Chemotherapy is one of the common treatment of cancer. Alkylating agents bind covalently with DNA, crosslink them and induce DNA strand breaks. Topoisomerase inhibitors prevent DNA replication. ${ }^{(10)}$ Microtubule targeting agents interrupt mitotic spindles and arrest mitosis. ${ }^{(11)}$ However, many traditional chemotherapy drugs have nonspecific distribution and uncontrollable release of drugs. Thus, side effect for normal tissue is serious problem in chemotherapy. To inhibit the side effect of anticancer drugs, it is investigated that combination therapy with anticancer drugs and antioxidants. ${ }^{(12-15)}$ Injury for normal tissue attenuate by this combination therapy. However, the effect of this combination therapy for cancer cells dose not investigate enough.

In this study, we investigated the combination effect of antioxidants and anticancer drugs. We select MP as an antioxidant. We previously reported that MP scavenge reactive oxygen species (ROS), especially mitochondrial ROS (mitROS). The activation of acid ceramidase was attenuated because of mitROS reducing by MP. Acid ceramidase degrades ceramides to sphingosine and fatty acids. Increase of ceramide accumulation induce apoptosis. From these results, cancer specific apoptosis was induced by MP. ${ }^{(16)}$ These results occurred by directly antioxidant effect. In this study, we evaluated indirectly antioxidant effect for anticancer drugs.

\section{Materials and Methods}

Cell culture. The murine 4T1 mammary carcinoma cell line was purchased from RIKEN CELLBANK. The 4T1 cells were cultured in high-glucose RPMI1640 (Wako Pure Chem Ind. Ltd., Osaka, Japan). The culture medium contained $10 \%$ of inactivated fatal bovine serum (Biowest LLC, Kansas City, MO) and 1\% of penicillin/streptomycin (Wako Pure Chem). The cell was cultured in $5 \% \mathrm{CO}_{2}$ cell culture incubator at $37^{\circ} \mathrm{C}$.

Cell viability assay. Cell viability was measured using the Cell Counting Kit-8 according to manufacturer's protocol. ${ }^{(17)} 4 \mathrm{~T} 1$ cells were cultured on 96 -well plates at $5 \times 10^{3}$ cells/well and incubated overnight. The supernatant was aspirated and the medium was replaced. To determine the cytotoxicity of MP (Wako Pure Chem), these media contained 0, 50, 100, 150, 200, 300 , and $400 \mu \mathrm{g} / \mathrm{ml}$ of MP respectively. Cells were incubated at $37^{\circ} \mathrm{C}$ for $24 \mathrm{~h}$. After incubation, the supernatant was aspirated and then incubated with medium containing 10\% Cell Counting Kit- 8 . The absorbance at $450 \mathrm{~nm}$ was measured by a DTX880 multi-mode microplate reader (Beckman Coulter, Brea, CA).

The effect of combination therapy of MP and anticancer drugs was evaluated. Doxorubicin (DOX), tamoxifen (TAM), paclitaxicel (PTA) and cyclophosphamide (CPA) (Wako Pure Chem) were selected as anticancer drugs. 4T1 cells were cultured on 96well plates at $5 \times 10^{3}$ cells/well and incubated overnight. The supernatant was aspirated and the medium containing MP and anticancer drugs was replaced. Cells were incubated at $37^{\circ} \mathrm{C}$ for $24 \mathrm{~h}$. After incubation, the supernatant was aspirated and then

*To whom correspondence should be addressed.

E-mail: hkurokawa.tt@md.tsukuba.ac.jp 
incubated with medium containing $10 \%$ Cell Counting Kit- 8 . The absorbance at $450 \mathrm{~nm}$ was measured by a DTX 880 multi-mode microplate reader.

Western blot assay. 4T1 cells were incubated overnight in $60-\mathrm{mm}$ dishes. Cells were incubated containing $200 \mu \mathrm{g} / \mathrm{ml} \mathrm{MP}$ and $5 \mathrm{mg} / \mathrm{ml} \mathrm{CPA} \mathrm{medium} \mathrm{for} 24 \mathrm{~h}$. The cells were rinsed with PBS three times and RIPA buffer was added in on ice, then boiling at $70^{\circ} \mathrm{C}$ for $10 \mathrm{~min}$. These whole cell lysates were used as Western bolt sample. For SDS-polyacrylamide gel electrophoresis, the samples were added into wells of NuPAGE ${ }^{\circledR}$ Novex $^{\circledR} 4-12 \%$ Bis-Tris gels (Thermo Fisher Scientific K.K., Kanagawa, Japan). The gels were electrophoresed at $100 \mathrm{~V}$ for $40 \mathrm{~min}$, and proteins were transferred onto a PVDF membrane (Bio-Rad Laboratories, Hercules, CA) by electrophoresis at 1.2 $\mathrm{mA} / \mathrm{cm}^{2}$ for $60 \mathrm{~min}$. The membrane was blocked for $60 \mathrm{~min}$ with PVDF blocking reagent from the Can Get Signal ${ }^{\circledR}$ (TOYOBO CO. LTD., Osaka, Japan) and probed with primary and secondary antibodies. Anti-rabbit B-cell lymphoma 2 (Bcl-2), Bcl2associated X protein (Bax) and p-Akt (ser473) (Cell Signaling Technology Japan K.K., Tokyo, Japan) antibodies $(1: 1,000)$ were added to the Can Get Signal ${ }^{\mathbb{R}}$ Immunoreaction Enhancer Solution 1 (TOYOBO), and then exposed to the membrane overnight. After the primary antibody solution was aspirated, the membrane was washed three times with PBS containing Tween 20. The secondary HRP-linked anti-rabbit IgG antibody (Cell Signaling Technology Japan K.K.) $(1: 1,000)$ was added to the Can Get Signal $^{\circledR}$ Immunoreaction Enhancer Solution 2 (TOYOBO) and exposed to the membrane for $60 \mathrm{~min}$. Lumina Forte Western HRP substrate (Millipore Co., Billerica, MA) was used to visualize the membrane. Images of the blots were captured on the FUSION FX7.EDGE (Vilber Lourmat, Co, Torcy, France). $\beta$ Actin (Cell Signaling Technology Japan K.K.) was detected as the control for protein loading.

Detection of apoptotic cells by Hoechst 332342 staining. The apoptosis of 4T1 cells was detected by the Hoechst 33342. $4 \mathrm{~T} 1$ cells were cultured on 6 -well plates at $5 \times 10^{4}$ cells/well and incubated overnight. The supernatant was aspirated and incubated with or without $200 \mu \mathrm{g} / \mathrm{ml} \mathrm{MP}$ containing $5 \mathrm{mg} / \mathrm{ml} \mathrm{CPA}$ for $24 \mathrm{~h}$. The supernatant was thereafter aspirated and then incubated with MSF buffer containing $10 \mu \mathrm{M}$ Hoechst 33342 for 10 min. Then cells were rinse with MSF three times and added MSF. Apoptosis, with condensed and fragmented nuclei, was analyzed using a fluorescence microscope (IX83, Olympus Inc., Tokyo, Japan). Fluorescence intensity of Hoechst33342 was excited at $340-390 \mathrm{~nm}$ filter and the emission was collected at $420 \mathrm{~nm}$ filter.

TLC assay. CPA, MP and MP with CPA solution were spotted on a silica gel TLC plate, which was developed in 1Propanol: water $(8: 1, \mathrm{v} / \mathrm{v})$. CPA was detected by ninhydrinethanol TS spray (Wako Pure Chem). TLC plate was imaged by a digital camera.

\section{Results}

MP act as a radical scavenger. The effect for 4T1 cells was examined. Cells were incubated for $24 \mathrm{~h}$ in medium containing MP. MP had no effect in cell viability for 4T1 until $200 \mu \mathrm{g} / \mathrm{ml}$. However cytotoxicity of MP occurred in dose-dependent manner from $300 \mu \mathrm{g} / \mathrm{ml}$ (Fig. 1). Intracellular ROS production was measured using ESR. The signal of DMPO was gradually low in dose-dependent manner (Fig. 2A). Especially, the DMPO signal in $200 \mu \mathrm{g} / \mathrm{ml}$ MP was significantly decreased compared with in 0 $\mu \mathrm{g} / \mathrm{ml}$ MP (Fig. 2B).

MP enhanced the cytotoxicity of CPA. The combination effect with anticancer drugs and MP was examined. $200 \mu \mathrm{g} / \mathrm{ml}$ MP did not showed cytotoxicity for $4 \mathrm{~T} 1$ and acted as a radical scavenger, thereby we chose $200 \mu \mathrm{g} / \mathrm{ml} \mathrm{MP}$ for investigating synergy effects with each anticancer drugs. The cytotoxicity of DOX, PTX and TAM did not enhance by MP (Fig. 3A-C). The cell viability of $5 \mathrm{mg} / \mathrm{ml} \mathrm{CPA}$ without MP was $59.6 \pm 7.1 \%$, while it with MP was $32.4 \pm 3.3 \%$ (Fig. 3D). The cytotoxicity of $5 \mathrm{mg} / \mathrm{ml} \mathrm{CPA}$ was significantly enhanced by MP.

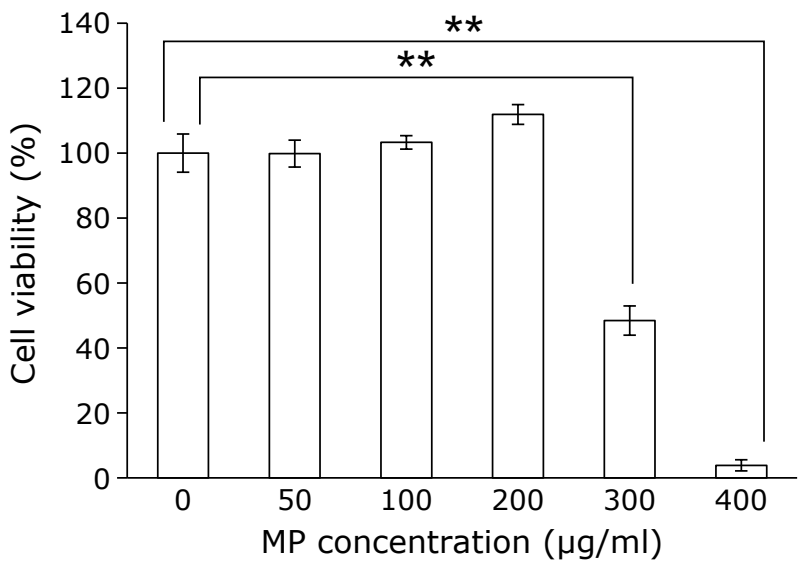

Fig. 1. Cytotoxicity of MP. 4T1 cells were exposed to culture medium containing several concentrations of MP for $24 \mathrm{~h}$, then WST assay was performed. Data are expressed as means \pm SD $(n=4) .{ }^{* *} p<0.01$.
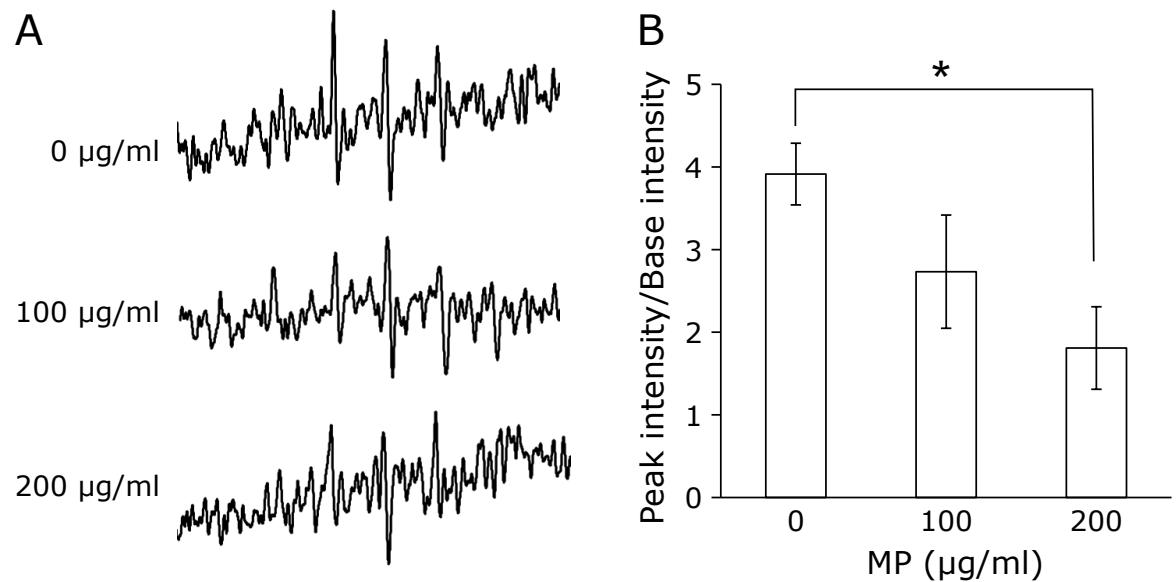

Fig. 2. Intracellular ROS production after treatment MP. (A) The electron spin resonance (ESR) spectra. (B) Relative ESR intensity. The signal of DMPO was gradually low in dose-dependent manner by MP. Data are expressed as means \pm SD $(n=3)$. ${ }^{*} p<0.05$. 

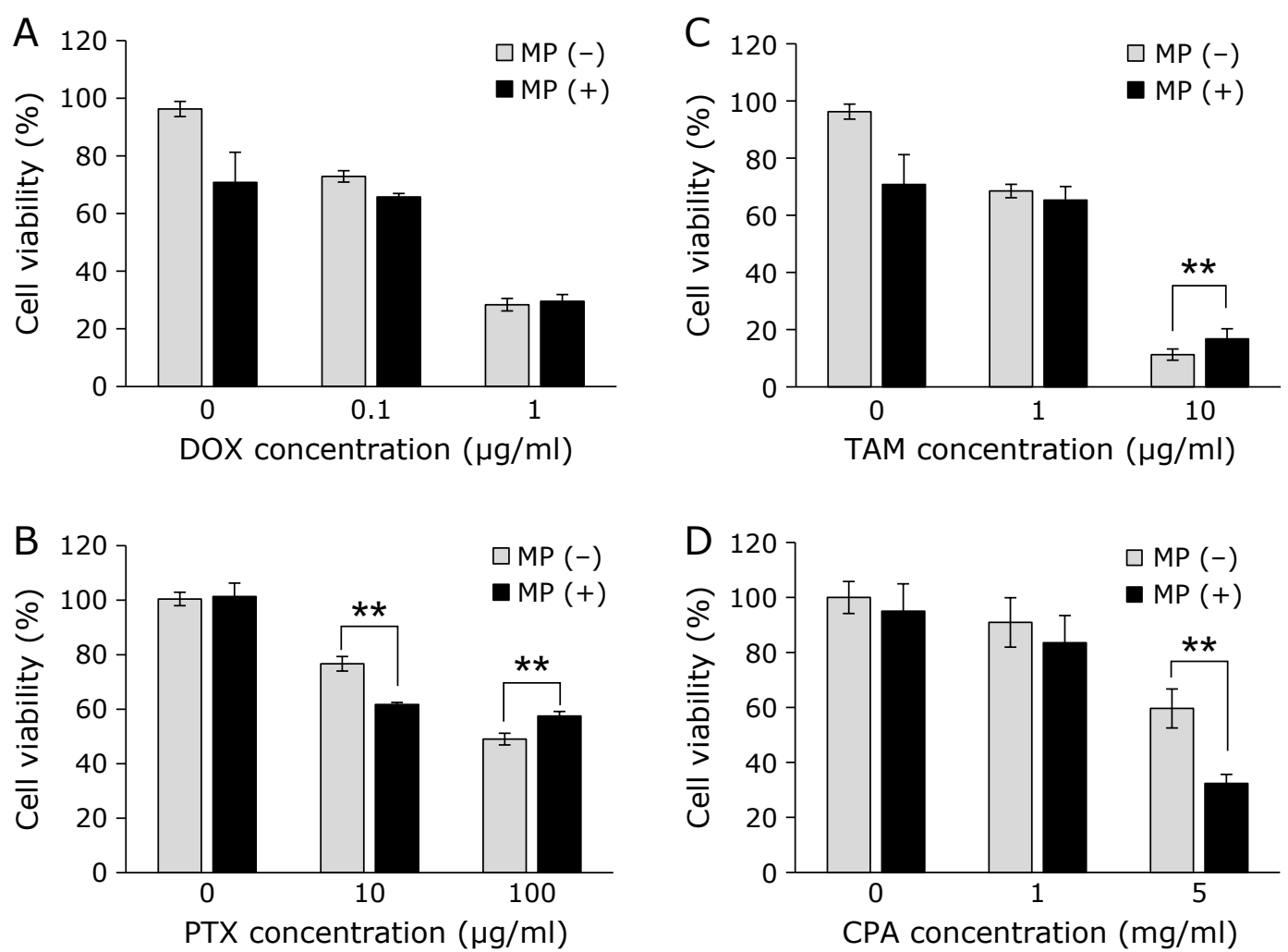

Fig. 3. The cytotoxicity of anticancer drugs combination with MP. The combination effect with anticancer drugs and MP was examined. (A) DOX, (B) PTX, (C) TAM, and (D) CPA. The concentration of MP was $200 \mu \mathrm{g} / \mathrm{ml}$. Data are expressed as means \pm SD $(n=4)$. ${ }^{* *} p<0.01$.

Combination therapy with MP and CPA decreased the BCL-2 expression and increased the Bax expression. Cells were exposed medium containing $5 \mathrm{mg} / \mathrm{ml} \mathrm{CPA} \mathrm{with} \mathrm{or} \mathrm{without}$ MP for $24 \mathrm{~h}$. Then the expression of Bcl-2 and Bax were analyzed by Western blotting. We observed the combination therapy with MP and CPA reduction in the levels of the antiapoptotic protein Bcl-2 (Fig. 4A and B). While a concomitant increase in the expression level of pro-apoptotic protein Bax was observed (Fig. 4C and D). The p-Akt signaling pathway plays a significantly role in regulating cell apoptosis. ${ }^{(18)}$ We measured the $\mathrm{p}$-Akt expression. The results showed that $\mathrm{p}$-Akt expression was decreased in cells treated with CPA and MP (Fig. 4E and F). These findings indicated that the combination with MP and CPA alters the expression of proteins involved in the regulation of apoptosis.

MP induces apoptosis in RGK1 cells. 4T1 cells were treated with or without $200 \mu \mathrm{g} / \mathrm{ml} \mathrm{MP} \mathrm{containing} 5 \mathrm{mg} / \mathrm{ml} \mathrm{CPA}$ for 24 $\mathrm{h}$, thereafter cell apoptosis was confirmed by Hoechst 33342 staining assay. Morphological changes indicating cell apoptosis such as condensation of both chromatin and nuclear fragmentations were found in MP treated cells (Fig. 5, white arrows). The result showed that MP treatment induced cancer cellular apoptosis.

The spot of MP with CPA solution showed different from MP solution. Thin mark is made at the bottom of the plate to apply the sample spots. Samples solutions are applied on the spots marked on the line. Then elute the plate using 1-Propanol and water. CPA spot was detected by ninhydrin reaction (Fig. 6A). The spot of CPA with MP was different from without CPA (Fig. 6B and C). Moreover, the spot of MP alone and MP with CPA were different at 100, 250, and 300 pixels (Fig. 6D and E).

\section{Discussion}

In this study, we demonstrated that the cytotoxicity of CPA enhanced by MP. The combination treatment with antioxidants and anticancer drugs attenuated the side effect for normal tissue by anticancer drugs. However, the investigation of this combination treatment for cancer tissue was not enough. This combination treatment may also attenuate the cytotoxicity of anticancer drugs for cancer tissue. In this study, we investigated the cytotoxicity of the combination treatment with antioxidant and anticancer drugs for cancer cell. MP is an antioxidant. ${ }^{(16)}$ We demonstrated the cytotoxicity of MP for 4T1 murine breast cancer cells. The cytotoxicity of MP did not show until $200 \mu \mathrm{g} / \mathrm{ml}$, however the cell viability compared with $0 \mu \mathrm{g} / \mathrm{ml}$ was decreased significantly from $300 \mu \mathrm{g} / \mathrm{ml}$ (Fig. 1). We measured the antioxidant effect of MP. MP act radical scavenger in $200 \mu \mathrm{g} / \mathrm{ml}$ which concentration did not show cytotoxicity (Fig. 1 and 2). From these results, we selected the MP as an antioxidant.

We investigated the cytotoxicity of combination treatment with MP and anticancer drugs for cancer cell. DOX, PTX, TAM, and CPA are used in the standard of care for breast cancer in Japan. The cell viability of DOX without MP and with MP did not change (Fig. 3A). The cytotoxicity in $10 \mathrm{ng} / \mathrm{ml}$ PTX enhanced by MP, however the cytotoxicity in $100 \mathrm{ng} / \mathrm{ml}$ PTX attenuated (Fig. 3B). The cell viability in $10 \mu \mathrm{g} / \mathrm{ml}$ TAM increased by MP (Fig. 3C). The cytotoxicity in $5 \mathrm{mg} / \mathrm{ml}$ CPA significantly enhance with MP $(32.4 \pm 3.3 \%)$ compared without MP (59.6 \pm $7.1 \%$ ). Researchers have been reported that antioxidants can prevent the side effect of anticancer drugs for normal tissue. In this study, we cleared that the antioxidant can enhance the cytotoxicity of specific anticancer drugs.

We measured the expression of BcL-2 and Bax. The BcL-2 regulate the permeabilization of the mitochondrial outer 
A Control MP CPA MP+CPA

$\mathrm{BCL} 2$

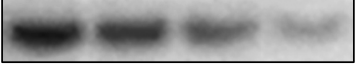

$\beta$-actin
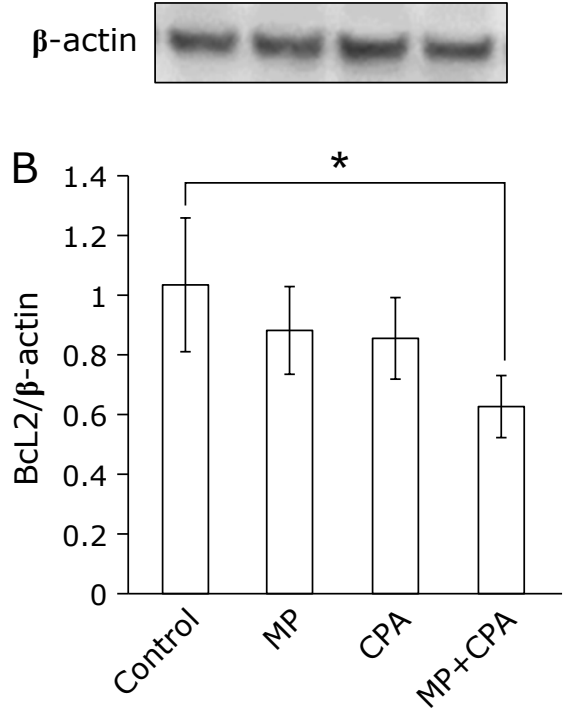

C Control MP CPA MP+CPA

Bax

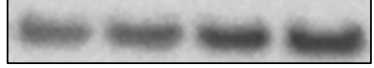

$\boldsymbol{\beta}$-actin

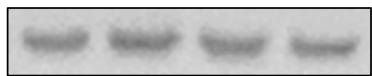

D

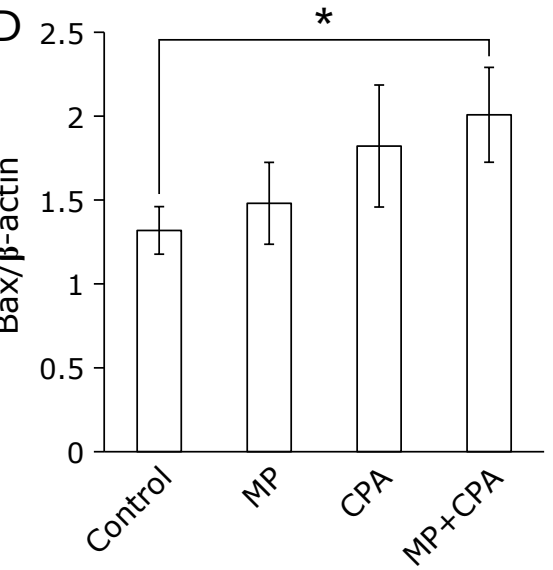

E Control MP CPA MP+CPA p-Akt

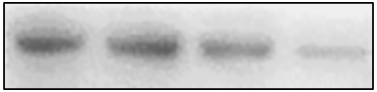

$\boldsymbol{\beta}$-actin
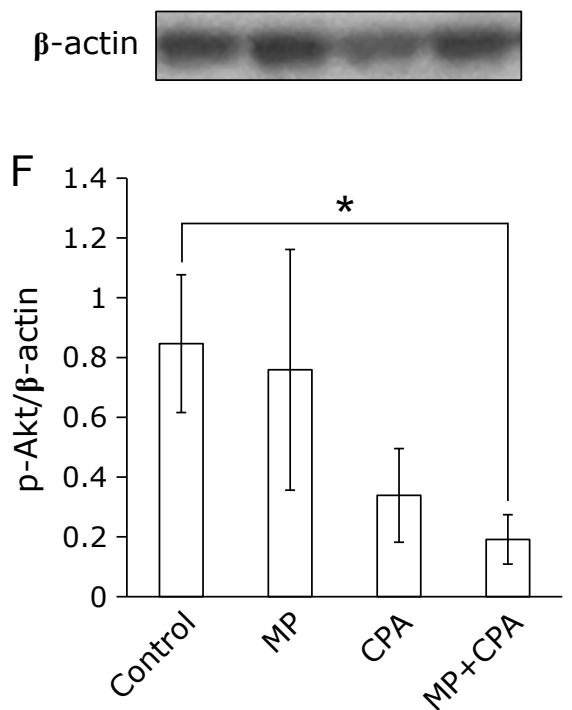

Fig. 4. Expression of $B c L-2, B a x$, and $p-A k t . B C L-2, B a x$, and $p-A k t$ were detected by Western blot. Compared to control, BcL-2 expression was decreased in combination with MP and CPA $(A, B)$, while Bax expression was increased $(C, D)$. Data are reported as the means \pm SD $(n=4)$. ${ }^{*} p<0.05$.
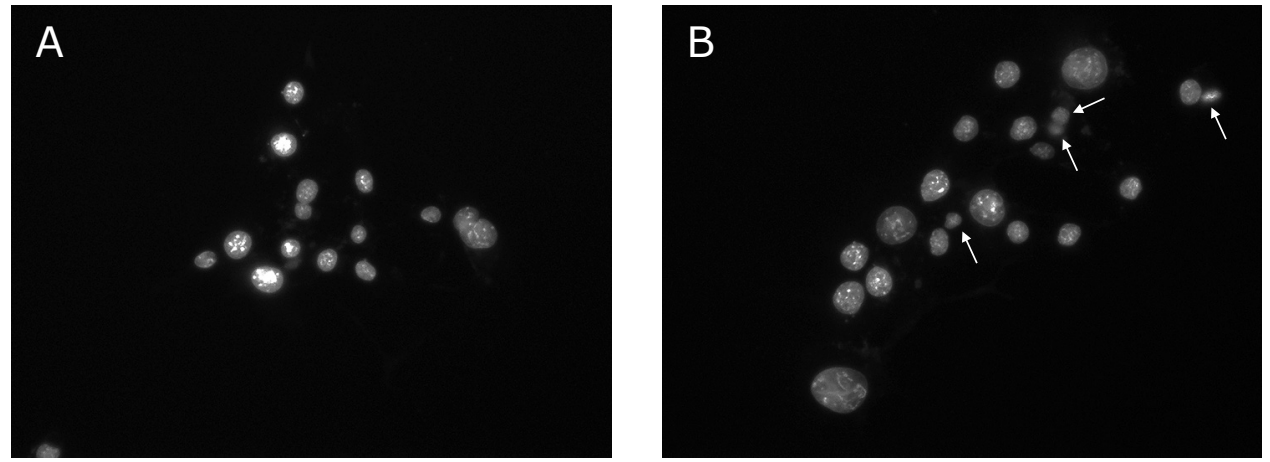

Fig. 5. Hoechst 332342 staining of $4 \mathrm{~T} 1$ cells. The cells undergoing apoptosis demonstrated apoptotic chromatin changes: blebbing, fragmentation and condensation under a fluorescence microscope. Cells were stained (A) without MP or (B) with $200 \mu \mathrm{g} / \mathrm{ml} \mathrm{MP} \mathrm{containing} 5 \mathrm{mg} / \mathrm{ml} \mathrm{CPA} \mathrm{for} 24 \mathrm{~h}$. Data were obtained in three independent experiments.

membrane and suppress apoptosis. Pro-apoptotic elements like Bax promote apoptosis. ${ }^{(19)}$ Compared with control, BcL-2 expression of the combination treatment with MP and CPA significantly decreased (Fig. 4A and B), while Bax expression was significantly increased (Fig. 4C and D). The p-Akt regulate BcL-2 and this expression was decreased the same manner of BcL-2 expression (Fig. 4E and F). Thus, we considered that the apoptosis by CPA and MP treatment was induced p-Akt signal pathway. Actually, cells treated with MP and CPA were induced apoptosis compared with CPA alone (Fig. 5). Antioxidants have antitumor effect. ${ }^{(20)}$ We also use MP as an antioxidant. However, $200 \mu \mathrm{g} / \mathrm{ml}$ MP did not show cytotoxicity in 4T1 (Fig. 1). Nevertheless, the combination treatment with MP and CPA enhanced the cytotoxicity (Fig. 3D). We considered two different cases. One is the activation of the cytochrome P450 (CYP). CYP2B6 is catalase of CPA. ${ }^{(17,21)} \mathrm{CPA}$ is a pro-drug that is metabolized by CYP2B6 to become cytotoxic and effective in cancer treatment. ${ }^{(22)}$ The 4- hydroxylation product is the active metabolite of CPA that yields an active alkylating agent, phosphoramide mustard. We analyzed the CYP2B6 expression in 4T1 cells, however CYP2B6 expression of combination treatment with CPA and MP have no different compared to control (data not shown). We cannot conclude that CYP2B6 activity is dependent on the CYP2B6 expression. At least, the combination treatment with CPA and MP have no effect the expression of CYP2B6.

Another case is the interaction between CPA and MP. By TLC assay, the spot of CPA with MP is different from the spot of CPA alone (Fig. 6A). The spot of CPA was showed 300-350 pixels, while the spot of CPA with MP was showed 250-300 pixels (Fig. $6 \mathrm{~B}$ and $\mathrm{C}$ ). Moreover, MP with CPA spot is also different from MP alone spot (Fig. 6A, D, and E). The spot of 250-300 pixels was overlap with MP and CPA. We thus concluded that CPA was interacted with some MP component present in 250-300 pixel. We considered that the interaction between MP and CPA can 


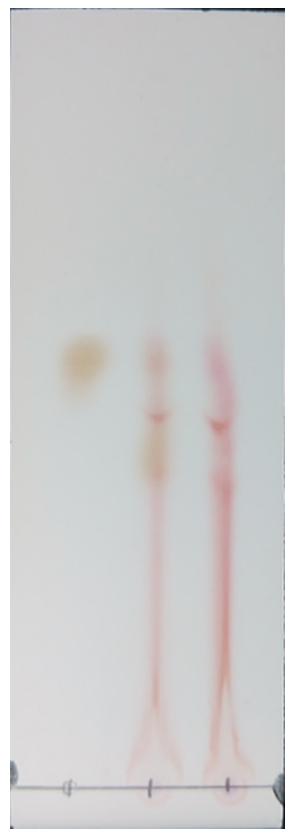

CPA $\quad$ CPM+MP MP

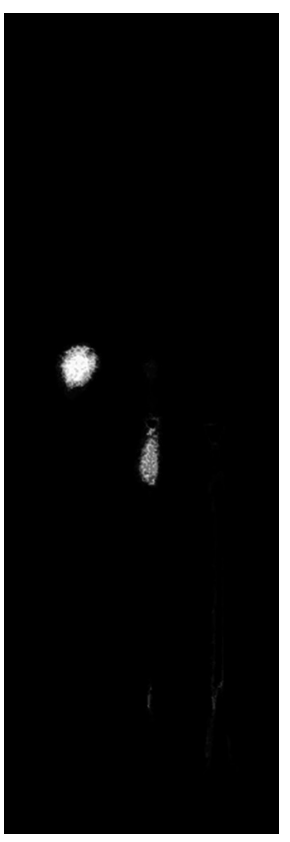

CPA $\quad \mathrm{CPM}+\mathrm{MP} \quad \mathrm{MP}$
Intensity (arb. units)

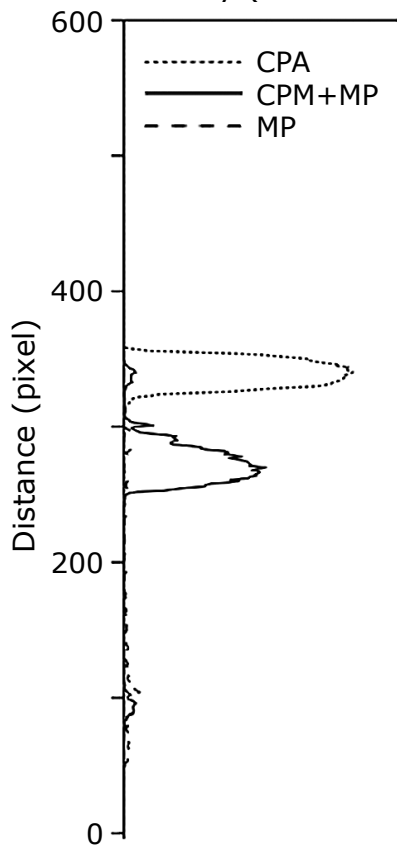

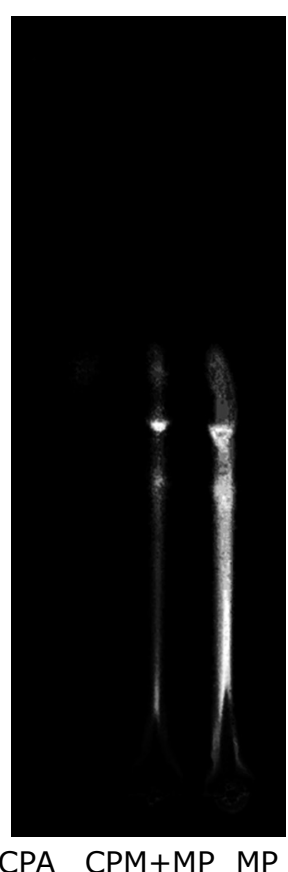

Intensity (arb. units)

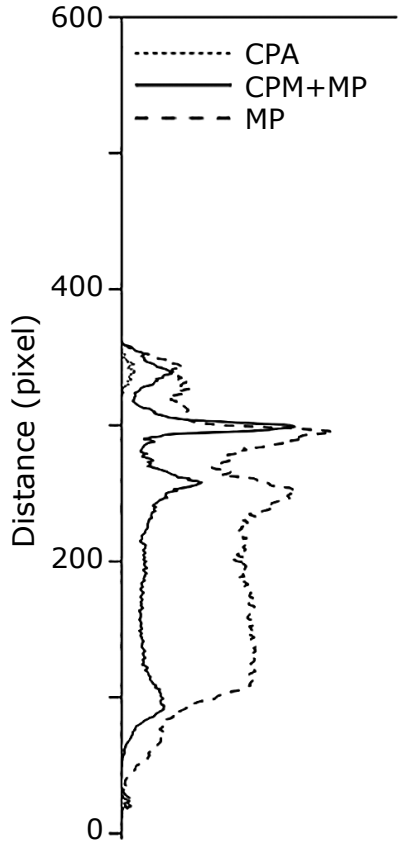

Fig. 6. TLC assay. (A) The bright field image. The extraction of CPA (B) and its line profile (C). The extraction of MP (D) and its line profile (C).

produce some cytotoxicity compounds or accelerate intracellular CPA accumulation.

We reported the antioxidant effect of MP. MP induce cancer specific apoptosis via accumulation of ceramide. ${ }^{(16)}$ This directly cell death was induced reduction of ROS production. On the other hands, cells were exposed $200 \mu \mathrm{g} / \mathrm{ml}$ MP in this study. This concentration did not show the cytotoxicity, however the cytotoxicity of CPA was enhanced. We demonstrated that antioxidant can enhance the cytotoxicity of anticancer drugs indirectly. We have already reported that antioxidants treatments upregulate

\section{References}

1 Akihisa T, Tokuda H, Yasukawa K, et al. Azaphilones, furanoisophthalides, and amino acids from the extracts of Monascus pilosus-fermented rice (redmold rice) and their chemopreventive effects. J Agric Food Chem 2005; 53: 562-565.

2 Li XM, Shen XH, Duan ZW, Guo SR. Advances on the pharmacological effects of red yeast rice. Chin J Nat Med 2011; 9: 161-166.

3 Endo A. Monacolin K, a new hypocholesterolemic agent that specifically inhibits 3-hydroxy-3-methylglutaryl coenzyme A reductase. J Antibiot (Tokyo) 1980; 33: 334-336.

4 Tobert JA. Lovastatin and beyond: the history of the HMG-CoA reductase inhibitors. Nat Rev Drug Discov 2003; 2: 517-526.

5 Taira J, Miyagi C, Aniya Y. Dimerumic acid as an antioxidant from the mold, Monascus anka: the inhibition mechanisms against lipid peroxidation and hemeprotein-mediated oxidation. Biochem Pharmacol 2002; 63: 1019-1026.

6 Aniya Y, Yokomakura T, Yonamine M, et al. Screening of antioxidant action of various molds and protection of Monascus anka against experimentally induced liver injuries of rats. Gen Pharmacol 1999; 32: 225-231.

7 Kohama Y, Matsumoto S, Mimura T, Tanabe N, Inada A, Nakanishi T. Isolation and identification of hypotensive principles in red-mold rice. Chem Pharm Bull (Tokyo) 1987; 35: 2484-2489.

8 Hsu LC, Hsu YW, Liang YH, Kuo YH, Pan TM. Anti-tumor and antiinflammatory properties of ankaflavin and monaphilone A from monascus
ABC transporter expression. ${ }^{(23)}$ Since ABC transporter is efflux transporter of anticancer drugs, ${ }^{(24)}$ these upregulation of $\mathrm{ABC}$ transporter attenuates the cytotoxicity of anticancer drugs. In conclusion, the cytotoxicity of cyclophosphamide treatment is enhanced by the combination treatment with MP.

\section{Conflict of Interest}

No potential conflicts of interest were disclosed. purpureus NTU 568. J Agric Food Chem 2011; 59: 1124-1130.

9 Meegan MJ, O'Boyle NM. Special Issue "Anticancer Drugs". Pharmaceuticals (Basel) 2019; 12: 134.

10 Singh S, Sharma B, Kanwar SS, Kumar A. Lead phytochemicals for anticancer drug development. Front Plant Sci 2016; 7: 1667.

11 Arnst KE, Banerjee S, Chen H, et al. Current advances of tubulin inhibitors as dual acting small molecules for cancer therapy. Med Res Rev 2019; 39: 13981426.

12 Ajith TA, Usha S, Nivitha V. Ascorbic acid and $\alpha$-tocopherol protect anticancer drug cisplatin induced nephrotoxicity in mice: a comparative study. Clin Chim Acta 2007; 375: 82-86.

13 Al-Kharusi N, Babiker HA, Al-Salam S, et al. Ellagic acid protects against cisplatin-induced nephrotoxicity in rats: a dose-dependent study. Eur Rev Med Pharmacol Sci 2013; 17: 299-310.

14 Pereira GC, Silva AM, Diogo CV, Carvalho FS, Monteiro P, Oliveira PJ. Drug-induced cardiac mitochondrial toxicity and protection: from doxorubicin to carvedilol. Curr Pharm Des 2011; 17: 2113-2129.

15 Injac R, Strukelj B. Recent advances in protection against doxorubicininduced toxicity. Technol Cancer Res Treat 2008; 7: 497-516.

16 Kurokawa H, Ito H, Matsui H. Monascus purpureus induced apoptosis on gastric cancer cell by scavenging mitochondrial reactive oxygen species. $J$ Clin Biochem Nutr 2017; 61: 189-195. 
17 Chang TK, Weber GF, Crespi CL, Waxman DJ. Differential activation of cyclophosphamide and ifosphamide by cytochromes P-450 2B and $3 \mathrm{~A}$ in human liver microsomes. Cancer Res 1993; 53: 5629-5637.

18 Zhang L, Zhou F, ten Dijke P. Signaling interplay between transforming growth factor- $\beta$ receptor and $\mathrm{PI} 3 \mathrm{~K} / \mathrm{AKT}$ pathways in cancer. Trends Biochem Sci 2013; 38: 612-620.

19 Pihán P, Carreras-Sureda A, Hetz C. BCL-2 family: integrating stress responses at the ER to control cell demise. Cell Death Differ 2017; 24: 14781487.

20 Xu DP, Li Y, Meng X, et al. Natural antioxidants in foods and medicinal plants: extraction, assessment and resources. Int J Mol Sci 2017; 18: 96.

21 Xie HJ, Yasar U, Lundgren S, et al. Role of polymorphic human CYP2B6 in cyclophosphamide bioactivation. Pharmacogenomics J 2003; 3: 53-61.
22 Sladek NE. Metabolism of oxazaphosphorines. Pharmacol Ther 1988; 37: 301-355.

23 Kurokawa H, Ito H, Terasaki M, Matsui H. Hyperthermia enhances photodynamic therapy by regulation of $\mathrm{HCP} 1$ and $\mathrm{ABCG} 2$ expressions via high level ROS generation. Sci Rep 2019; 9: 1638.

24 Wang YJ, Zhang YK, Kathawala RJ, Chen ZS. Repositioning of tyrosine kinase inhibitors as antagonists of ATP-binding cassette transporters in anticancer drug resistance. Cancers (Basel) 2014; 6: 1925-1952.

This is an open access article distributed under the terms of the Creative Commons Attribution-NonCommercial-NoDerivatives License (http://creativecommons.org/licenses/by-nc-nd/4.0/). 